\title{
A Novel Design of Rescue Capsule considering the Pressure Characteristics and Thermal Dynamic Response with Thermomechanical Coupling Action Subjected to Gas Explosion Load
}

\author{
Xiaowei Zhai, ${ }^{1,2,3}$ Shibo Wu, ${ }^{1,2,3}$ Kai Wang, ${ }^{1,2,3}$ Xiaokun Chen, ${ }^{1,2,3}$ and Haitao Li ${ }^{1,2}$ \\ ${ }^{1}$ College of Safety Science and Engineering, Xian University of Science and Technology, No. 58, Yanta Mid. Rd., \\ Xian, Shaanxi 710054, China \\ ${ }^{2}$ Shaanxi Key Laboratory of Prevention and Control of Coal Fire, Xian University of Science and Technology, \\ Xian, Shaanxi 710054, China \\ ${ }^{3}$ Engineering Research Center of the Ministry of Education, Xian University of Science and Technology, \\ 58, Yanta Mid. Rd., Xian, Shaanxi 710054, China \\ Correspondence should be addressed to Xiaowei Zhai; zhaixw@xust.edu.cn
}

Received 22 March 2017; Accepted 19 June 2017; Published 31 July 2017

Academic Editor: Tony Murmu

Copyright (C) 2017 Xiaowei Zhai et al. This is an open access article distributed under the Creative Commons Attribution License, which permits unrestricted use, distribution, and reproduction in any medium, provided the original work is properly cited.

To ensure the structural safety and reliability of coal mine rescue capsule in disastrous surroundings after gas explosion, in this paper, the thermomechanical coupling effect on a certain structure subjected to gas explosion was analyzed, and then a novel rescue capsule with a combination of radius and square features was designed according to the underground surroundings and relevant regulations on mine rescue devices. Foremost, the coupling mechanism of thermal-fluid-solid interaction between gas explosion shock wave and rescue capsule and the thermal dynamic response of the capsule subjected to explosion load of gas/air mixture was investigated and revealed by employing LS-DYNA. The variation laws and characteristics of stress field, displacement field, and temperature field of the capsule were analyzed based on the simulation results. Results show that the structural safety, tightness, and reliability of the capsule meet the requirements of the national safety regulations. The design method presented in this work provides a new thought for design of coal mine rescue capsule.

\section{Introduction}

Refuge capsule, the "Noah's Ark" for underground coal mine, could decrease the death rate in a gas explosion accident to a large extent, which has become one of the "six systems" for underground coal mine safety production at home and abroad $[1,2]$. Up till now, refuge capsule has been widely produced and applied in the domestic and foreign coal mines enterprises [3]. Nowadays, China, Australia, South Africa, and Canada have made severer safety policies and corresponding standards for refuge capsule [4-6]. However, it remains a mystery whether the structural safety and stability of the refuge capsule could be ensured in a disastrous environment. Moreover, how to guarantee the antiknock performance and high temperature resistance of refuge capsule in the rescue process [7]? Therefore, it is of great significance to conduct analysis and simulation evaluation for the antiknock performance and high temperature resistance of a refuge capsule.

The rescue process cannot make progress if the structural parameters of the refuge capsule was designed poorly and would lead to local or global failure once the gas/dust explosion occurs. Consequently, it is necessary for developers to perform accurate analysis and assessment for the antiknock performance and high temperature resistance of a refuge capsule. Nowadays, many researchers have analyzed the shock load and failure mechanism for a capsule by theoretical analysis, experimental investigation, and numerical simulation. Fang et al. [8] studied the workload for a capsule through numerical simulation and got the form of load 
exerted on the airtight blast door. Richard Liew and Chen [9] validated that ALE algorithm can be used for solving the interaction between fluid and structure by grid optimization. Hou et al. [10] analyzed the parameters of the different shape of the capsule, such as the volume, stress, and maximum deformation using numerical calculation. $\mathrm{Xu}$ and $\mathrm{Hu}$ [11], Fan [12], and Guo et al. [13] tested the antiknock performance of the rescue capsule in a full-size tunnel, and the stress and displacement value of the measured points on surface of the capsule were obtained. Theoretical analysis is a rather difficult methodology for the thermomechanical analysis of rescue capsule because of too many hypotheses and conditions, causing assignable errors easily. Meanwhile, physical experiment especially antiknock performance on rescue capsule is a time-consuming, high-cost, and dangerous approach and cannot be repeated. Numerical simulation provides an effective method for antiknock analysis of the rescue capsule. Some scholars have discussed the dynamic response of rescue capsule under different forms of explosive load, such as the equivalent triangular wave [14-18] and trapezoidal wave [19], even impulsive load [20]. Those simplified studies had saved too much computational cost while ignoring the fluidsolid coupling process between explosion shock wave and the structure. At the same time, there were scholars who employed TNT equivalent method [21-23] to interpret fluidstructure interaction process; worse still, the TNT equivalent method would be affected greatly by pressure rise rate and duration time. In fact, the high temperature and high pressure gas produced after gas explosion interacts with the capsule are a thermohydromechanical coupling process; however, the studies described above have ignored the heat exchange in the process shock wave interaction with the capsule.

Moreover, there were few researches about thermal-fluidsolid coupling analysis on the three types of load explosion and thermal and shock loads that interact with a structure in the existing registration, especially the thermal dynamic response of some complicated structures, such as rescue capsule or refuge chamber. $\mathrm{Li}$ [24] and $\mathrm{Du}$ [25] conducted the antiknock and transient thermal analysis for a capsule using decoupling method, but ignoring the thermomechanical coupling effect. Fang et al. [26] established the buckling equation of stiffened cylindrical shell under axial load, and they studied the influencing factors by using hybrid method. Fang et al. [27] developed a three-dimensional model of cylindrical shell capsule and carried out the dynamic response analysis under explosion load. Liu [28] investigated the thickness of thermal insulation layer, position of tunnel, and the fixed way on the insulation effect of the capsule by Fluent. Bai [29] discussed the high temperature impact resistance of the capsule using a thermal analysis module in ABAQUS, and the variation laws of temperature on outer surface, thermal insulation layer, and inner surface were simulated and deduced. Song and Ge [30] built a composite metal cabin and studied its dynamic response under axial blast loading. However, the numerical simulation studies mentioned above have analyzed the stress and deformation characteristics of the capsule under a single load but could not reflect the effect of the gas explosion on the capsule and the fluid-structure interaction. In this work, the theory of thermal-stress coupling effect of the gas explosion was put forward, and ALE coupling algorithm was applied to reveal the heat flux of gas explosion shock wave and capsulesolid coupling theory; what is more, the thermodynamic response rescue was calculated to evaluate the structural safety and dynamic response of a capsule, which will provide a guidance for safety design of coal mine rescue devices.

\section{The Theory of Thermal Force Coupling Effect under Gas Explosion Load}

Gas explosion is a transient and nonlinear release process, influenced by the driving force. It takes an important place in structural safety [31]. On the other hand, a relatively high temperature gradient and pressure gradient will emerge after the gas explosion, a large amount of heat energy will be converted and carried by the moving gas, plastic deformation occurs on the structure under the gas explosion overpressure, and dynamic pressure and temperature will interact with the explosion field. Therefore, the effect of gas explosion shock wave and structure is actually a heat-flowsolid coupling process driven by thermomechanical effect [32]. Impacted by the load produced by gas explosion, a higher pressure occurs on the structure under dynamic load. The solid material presents the mechanical properties of fluid in case of ignoring the higher order ratio of material strength and the pressure. However, the strength effect will be strengthened once the high unloading pressure is too small. Hence, in the calculation process, governing equations of fluid dynamics are not only essential but also the elastic and plastic strength of the material. Therefore, the theoretical model of thermomechanical coupling for gas explosion is mainly composed of the fluid dynamics equation, the state equation, and the elastoplastic constitutive relations.

The Lagrange expressions for continuity equation, motion equation, and energy equation are as follows:

$$
\begin{aligned}
\frac{d \rho}{d t}+\rho \operatorname{div} V & =0, \\
\rho \frac{d V}{d t} & =\rho g+\nabla \cdot \sigma, \\
\rho \frac{d e}{d t} & =\operatorname{div}(k \nabla T)+\sigma:(\nabla \otimes V),
\end{aligned}
$$

where $\rho$ is density, $T$ is temperature, $e$ is ratio of internal energy, $k$ is thermal conductivity, $t$ is time, $V$ is velocity, $g$ is acceleration of gravity, and $\sigma$ is total stress tensor.

Considering the thermomechanical coupling effect of gas explosion, it is necessary to introduce a Fourier heat conduction factor. Since the material of the capsule is isotropic, therefore it follows the law of Friye's conduction:

$$
q=-k \operatorname{grad} T,
$$

where $q$ is per unit area of heat flux. $T$ is temperature, $k$ is thermal conductivity, and the minus sign refers to heat transfer along the direction of hot zone to the cold region.

Volume deformation will occur on a structure if impacted by gas explosion shock wave, and the volume deformation is correlated with temperature, pressure, and internal energy. 
Large deformation will occur on a structure under blast load, and the material will enter into the phase of plastic flow quickly. Thermoviscoplastic constitutive relation is a kind of plastic constitutive relation, which has considered the plastic strain hardening, plastic strain rate hardening, and temperature softening. Here Johnson-Cook model is employed to describe the state of flow stress, which can be stated as follows:

$$
Y=\left[Y_{0}+B\left(\varepsilon_{p}\right)^{n}\right]\left[1+C \ln \left(\varepsilon^{*}\right)\right]\left[1-\left(T^{*}\right)^{m}\right],
$$

where $Y_{0}$ is the static yield strength, $\varepsilon^{*}=\dot{\varepsilon_{p}} / \dot{\varepsilon_{0}}, \dot{\varepsilon_{p}}$ is the equivalent plastic strain rate.

Moreover, in the compressible fluid elastic plastic model, when a structure was impacted by gas explosion shock wave, heat is generated mainly by two parts, one is the plastic shearing action, and the other one is the impact compression. Then (3) can be converted into the following form:

$$
\rho \frac{d e}{d t}=\operatorname{div}(K \nabla T)+\sigma^{\prime}:(\nabla \otimes V)+p I:(\nabla \otimes V),
$$

where the first term on the right end is Friye conduction effect and the second and the third are plastic deformation efficacy and impact compression efficacy, respectively.

In summary, the state of a structure will change when affected by thermomechanical coupling effect after gas explosion, and the propagation and temperature distribution of shock wave would be affected by the state of the structure; therefore, it is necessary to take into account the influence of thermal shock on the structure once gas explosion happens.

\section{Models and Equations}

3.1. Model Design and Mesh Generation. The finite element model of rescue capsule is established on account of the actual structure, relevant regulations, and elastic mechanics. The shape and geometry of rescue capsule are shown in Figure 1. As it can be seen from the figure, the main portion is composed of two parts: the capsule body and staff capsule. The entity structure, such as flange, hinge, rib, handle, and door, is described with solid element and the skin is characterized by shell element. The total length of the capsule is $10 \mathrm{~m}$, the height, length, and width of the equipment compartment are $2.1 \mathrm{~m}, 2.8 \mathrm{~m}$, and $1.8 \mathrm{~m}$, respectively, and 2 reinforcing ribs are distributed on four sides of the capsule. The diameter and length of the staff capsule are $1.8 \mathrm{~m}$ and $7.2 \mathrm{~m}$. The staff capsule and capsule body are welded together by connecting piece and thus constituting a capsule.

According to some design methods and antiknock regulations about rescue device, the tunnel can be simplified as a semiclosed pipe model. The corresponding size is presented in Figure 2. As it can be seen from the figure, the tunnel is composed of two parts. The whole length of part 1 (from A to B) is $28 \mathrm{~m}$, which was composed of $200 \mathrm{~m}^{3}$ gas/air mixture with $9.5 \%$ concentration to give rise to a gas explosion, and part 2 (from $B$ to $C$ ) is from the end of the gas/air mixture zone to the front face of the capsule, with a length of $100 \mathrm{~m}$.

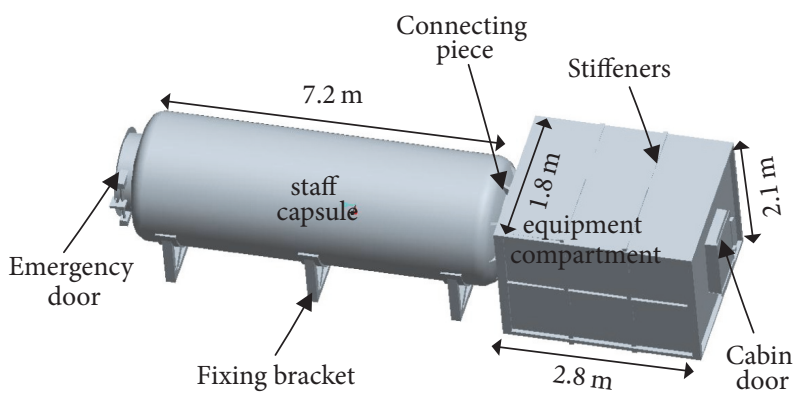

Figure 1: Geometry of rescue capsule.

Part 3 (from C to D) is from the front face of the capsule to the exit of the tunnel, with a length of $20 \mathrm{~m}$. It is worth mentioning that the bottom of the capsule is fixed on ground, making a hypothesis that the initial velocity of capsule is zero and the tunnel wall is smooth and rigid.

Shell element is described with the tetrahedral element mesh, and the shell element 163 is applied to simulate the shell, mapping mesh is employed to divide each unit cell, and cell size is $0.04 \mathrm{~m}$. Element 164 is used to simulate the capsule door cabin and flange and methane/air mixture. Solid element meshed is characterized with hexahedral mesh, and unit size is $0.1 \mathrm{~m}$. The results are shown in Figure 3.

3.2. Material Model and Equation of State. The main component of the mixture is methane. It has been proved that if the concentration of methane ranges from $5 \%$ to $15 \%$ in the premixed gases, a minimal energy will easily trigger a gas explosion. The explosion speed and pressure of methane/air mixture can reach the maximum when the methane concentration reaches about $9.5 \%$.

The air and gas flow state are described by material MAT_NULL model in the material database of LS/DYNA and the linear polynomial equation of state EOS_LINEAR POLYNOMIAL. The linear polynomial equation of state is expressed as follows:

$$
p=C_{0}+C_{1} \mu+C_{2} \mu^{2}+C_{3} \mu^{3}+\left(C_{4}+C_{5} \mu+C_{6} \mu^{2}\right) E,
$$

where $E$ is internal energy, $C_{0} \sim C_{6}$ are state parameters of (7), and $\mu=\rho / \rho_{0}-1$. The parameter values of null material model and linear polynomial equation of state are shown in Table 1.

The dynamic process of gas explosion is a typically highstrain rate phenomenon. High-strain rate has a significant influence on the mechanical properties of the material [33]. The yielding strength of a solid material will increase substantially under high-strain rate. Therefore, in this paper, the Johnson-Cook [34] model is applied to simulate the strain characteristics of steel (see (5)), and the mechanical properties of concrete material parameters are shown in Table 2.

\section{Results and Discussion}

4.1. Coupling Interaction of Fluid-Structure under Coupling Action of Thermomechanical. Figure 4 shows the interaction 

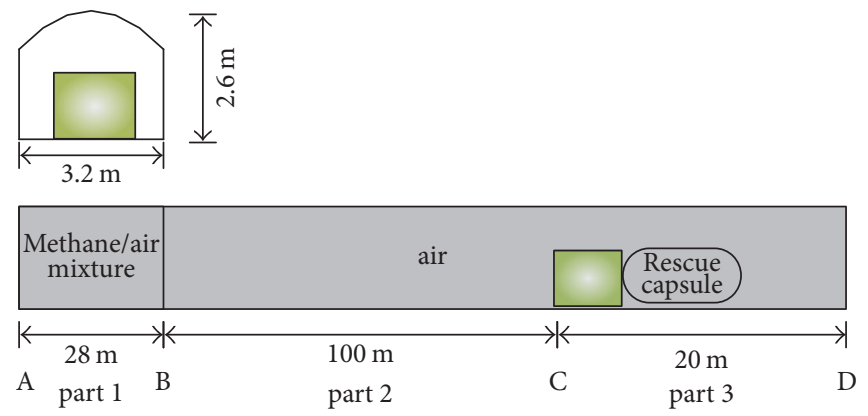

FIGURE 2: Length and cross section of the tunnel.
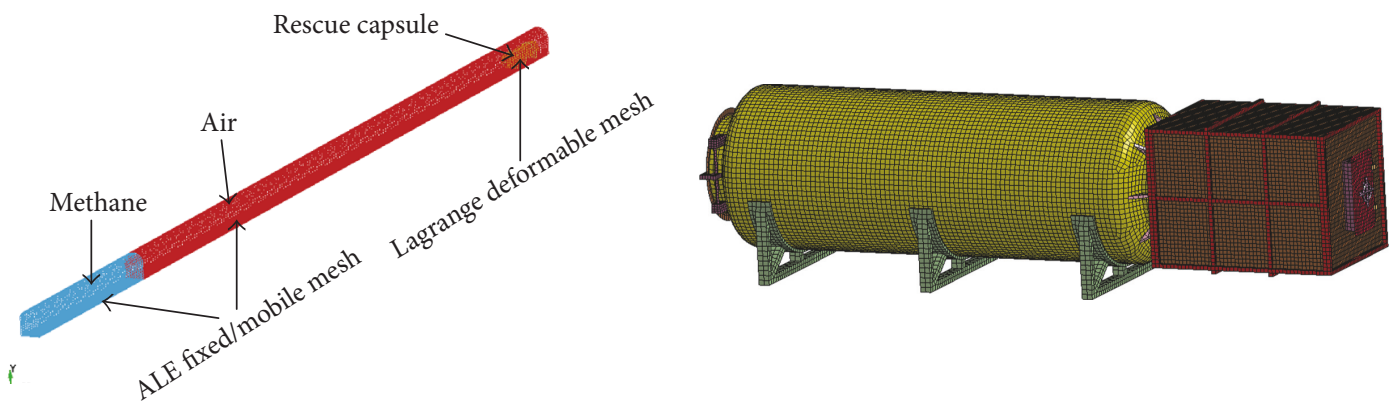

Figure 3: Mesh of rescue capsule and tunnel.

LS-DYNA keyword deck by LS-PrePost

Time $=284.42$

Contours of Pressure

$\min =-0.1$, at elem\# 294883 $\max =0.756927$, at elem\# 215864

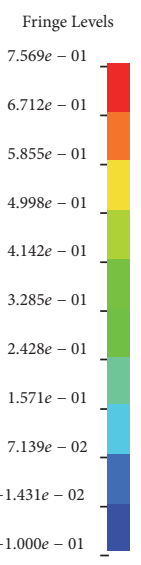

(a) $t=284.42 \mathrm{~ms}$

LS-DYNA keyword deck by LS-PrePost

Time $=304.56$

Contours of Pressure

$\min =-0.1$, at elem\# 294835

$\max =0.843779$, at elem\# 270883

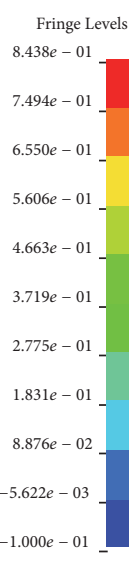

(c) $t=304.56 \mathrm{~ms}$
LS-DYNA keyword deck by LS-PrePost

Time $=293.16$

Contours of Pressure

$\min =-0.1$, at elem\# 294899

$\max =0.715992$, at elem\# 215859
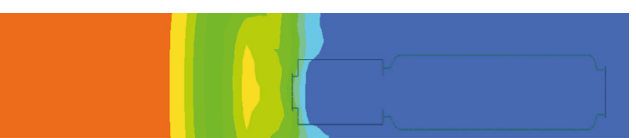

(b) $t=293.16 \mathrm{~ms}$

LS-DYNA keyword deck by LS-PrePost

Time $=323.94$

Contours of Pressure

$\min =-0.1$, at elem\# 294707

$\max =0.760464$, at elem\# 270883

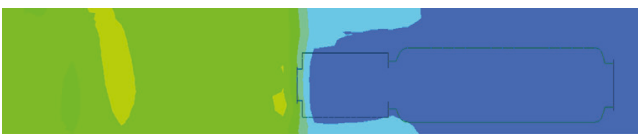

(d) $t=323.94 \mathrm{~ms}$

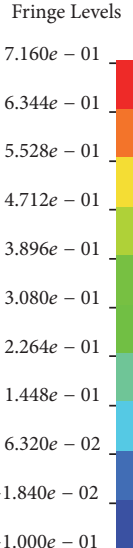

$-1.000 e-01$

Fringe Levels

$7.605 e-01$

$6.744 e-01$

$5.884 e-01$

$5.023 e-01$

$4.163 e-01$

$3.302 e-01$

$2.442 e-01$

$1.581 e-01$

$7.209 e-02$

$-1.395 e-02$

FIGURE 4: Pressure contour of the blast wave interaction with the rescue capsule in the tunnel. 
LS-DYNA keyword deck by LS-PrePost Time $=284.42$

Contours of temperature

$\min =-9.08511 e-15$, at node\# 2278939

$\max =2005.23$, at node 2283012

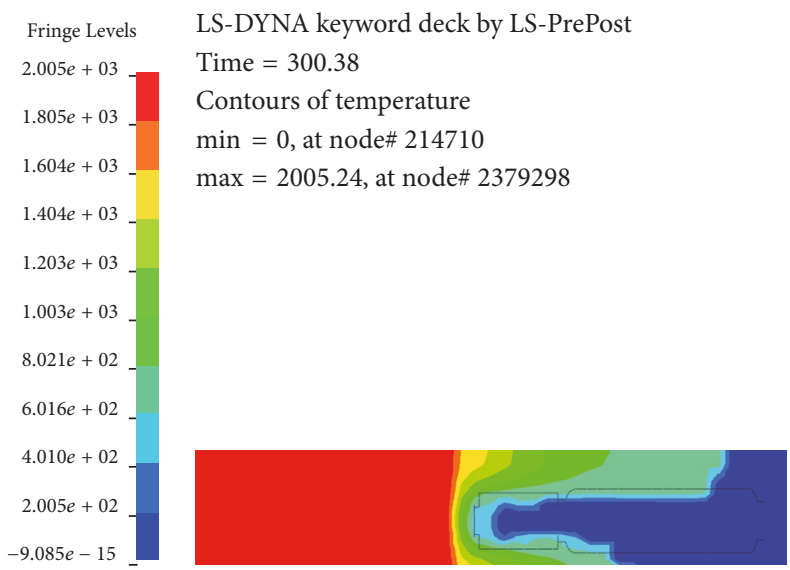

(b) $t=293.16 \mathrm{~ms}$

(a) $t=284.42 \mathrm{~ms}$

LS-DYNA keyword deck by LS-PrePost

Time $=312.92$

Contours of temperature

$\min =0$, at node\# 214710

$\max =2005.23$, at node\# 2283061

Time $=323.94$

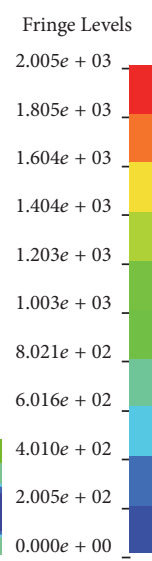

$0.000 e+00$

(c) $t=304.56 \mathrm{~ms}$

LS-DYNA keyword deck by LS-PrePost

Contours of temperature

$\min =0$, at node\# 214710

$\max =2005.22$, at node\# 2283068

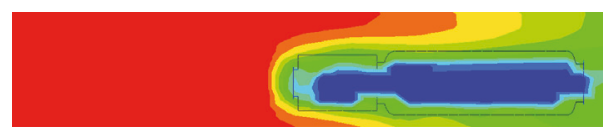

(d) $t=323.94 \mathrm{~ms}$

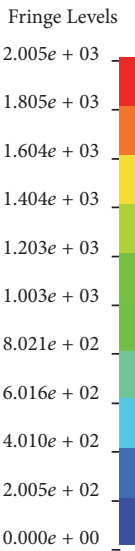

Fringe Levels $2.005 e+03$ $1.805 e+03$ $1.604 e+03$ $1.404 e+03$ $1.203 e+03$ $1.003 e+03$ $8.021 e+02$ $6.016 e+02$ $4.010 e+02$ $2.005 e+02$ $0.000 e+00$

FIgURE 5: Temperature contour of the blast wave interaction with the rescue capsule in the tunnel.

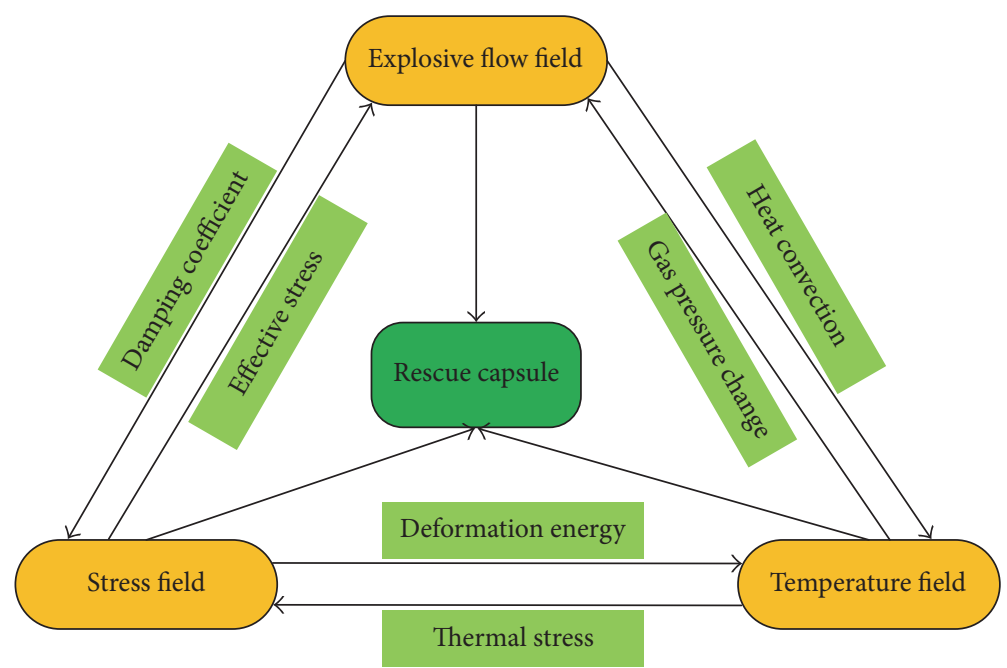

FIgURE 6: Coupling relationship between the explosion flow field, stress field, and temperature field. 


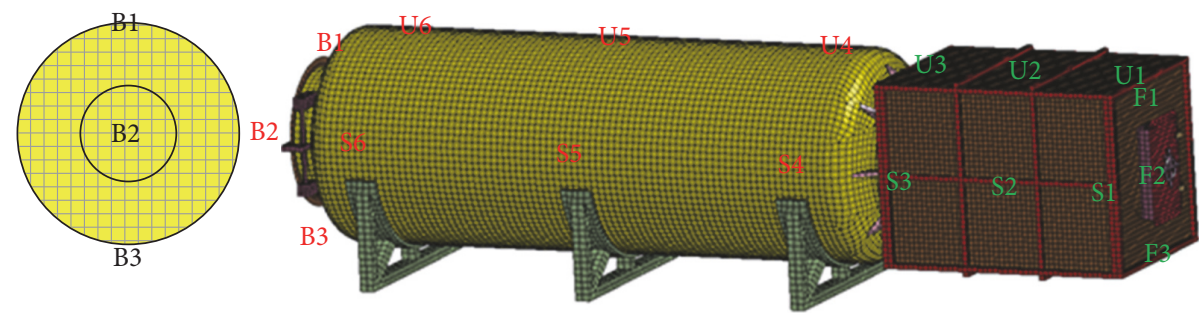

FIGURE 7: Pressure monitoring points distribution of the rescue capsule.
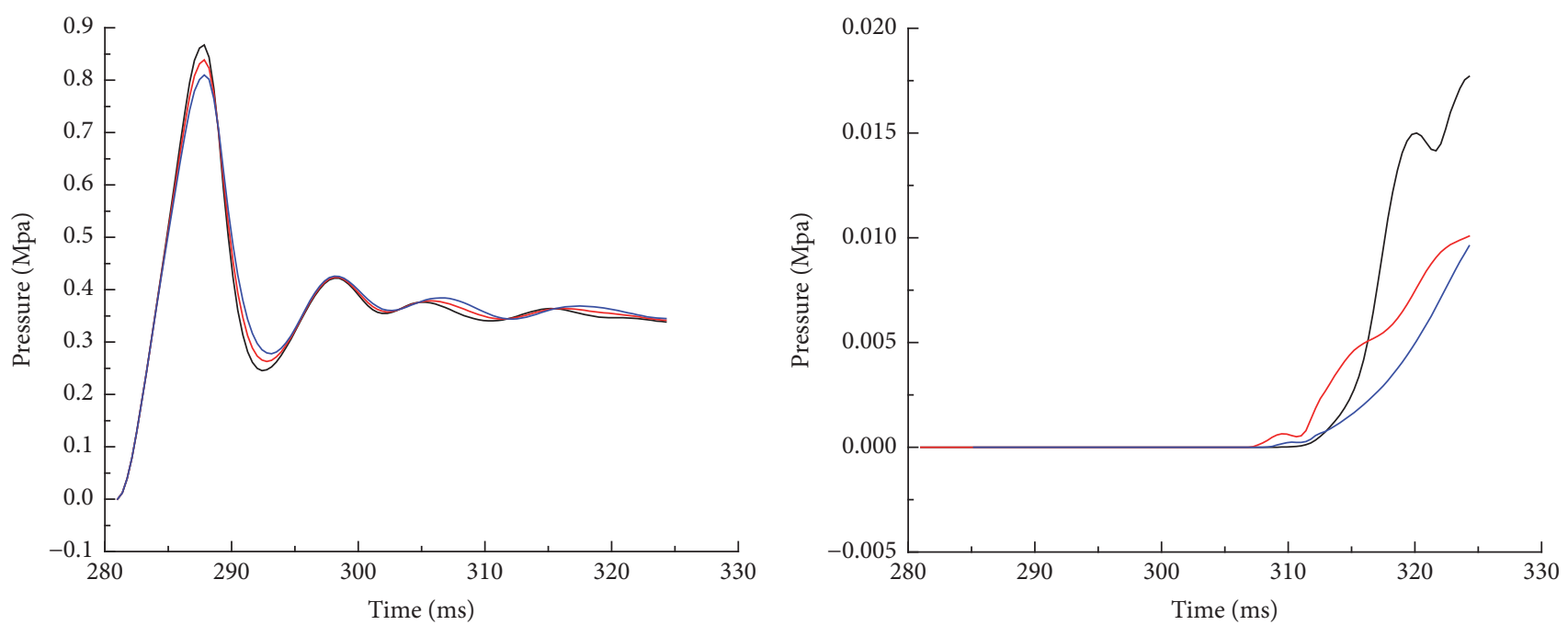

$$
\begin{array}{r}
-\mathrm{F} 1 \\
-\mathrm{F} 2 \\
\mathrm{~F} 3
\end{array}
$$$$
\begin{array}{rr}
-\mathrm{B} 1 \\
-\mathrm{B} 2 \\
-\mathrm{B} 3
\end{array}
$$

(a)
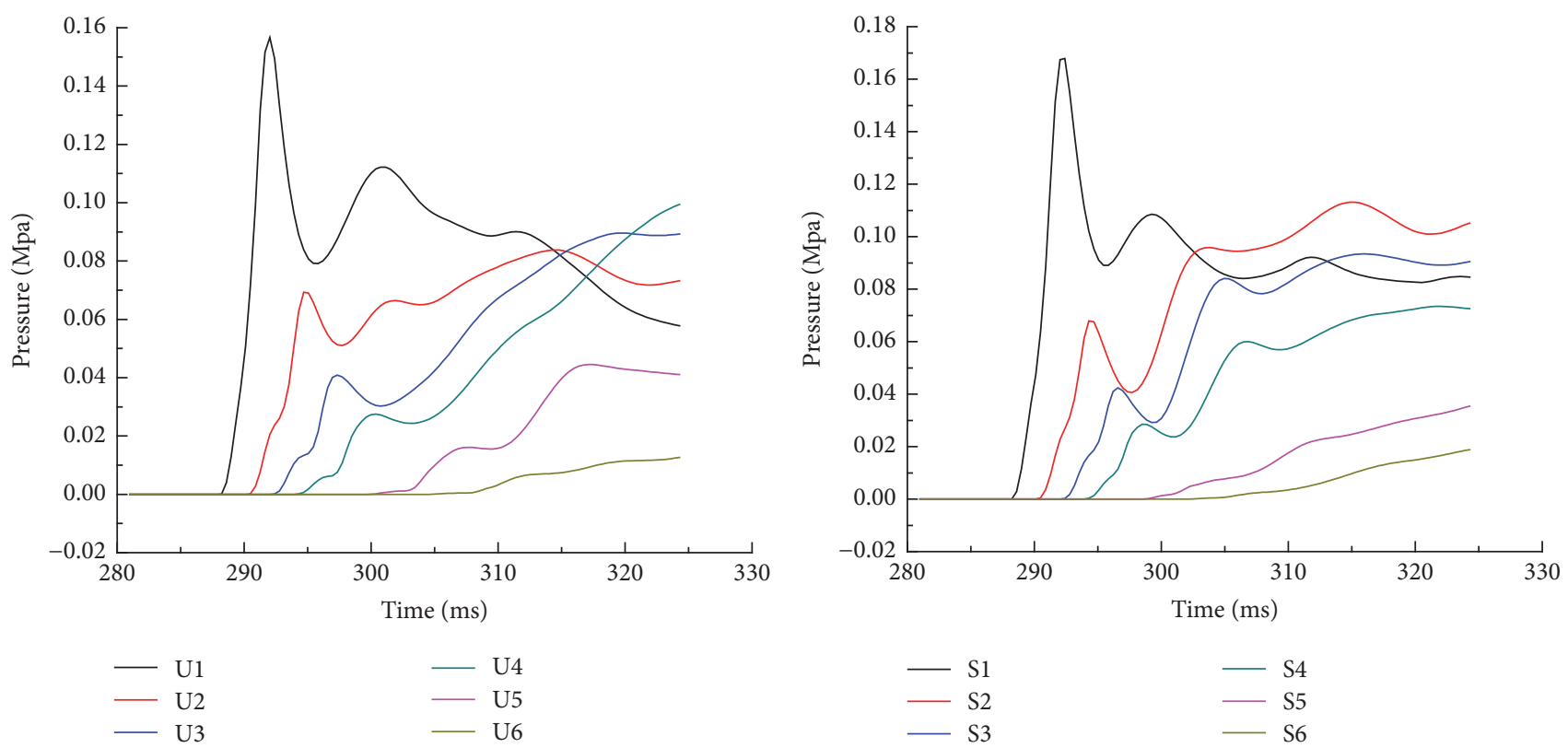

(c)

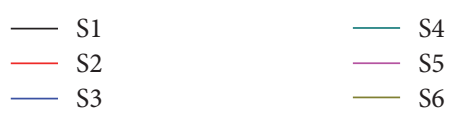

(d)

FIGURE 8: Pressure-time curve in positions on different surface. 


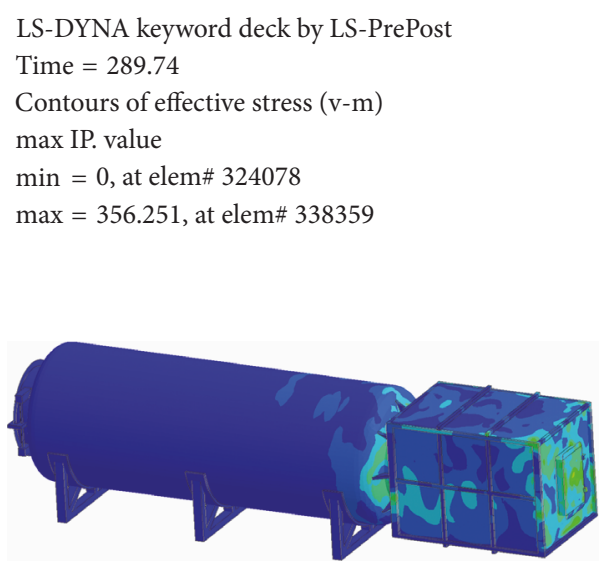

(a) $t=289.74$

LS-DYNA keyword deck by LS-PrePost

Time $=312.54$

Contours of effective stress ( $\mathrm{v}-\mathrm{m})$

max IP. value

$\min =0$, at elem \# 324078

$\max =300.063$, at elem $\# 337271$

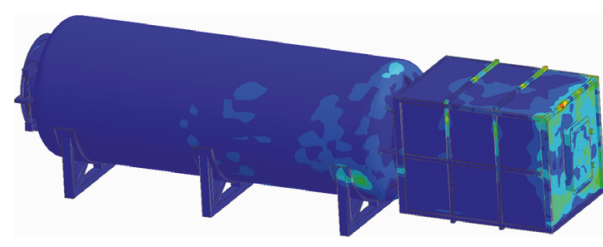

(c) $t=312.54$

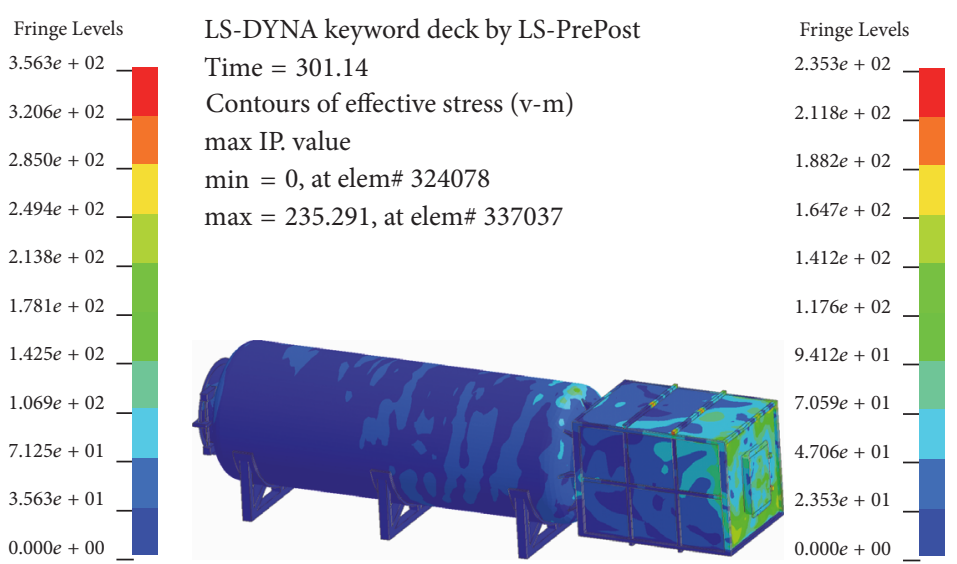

(b) $t=301.14$

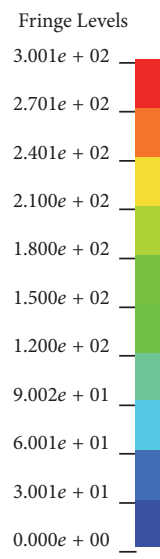

LS-DYNA keyword deck by LS-PrePost

Fringe Levels

Time $=323.94$

Contours of effective stress (v-m)

max IP. value

$\min =0$, at elem\# 324078

$\max =341.75$, at elem\# 337271

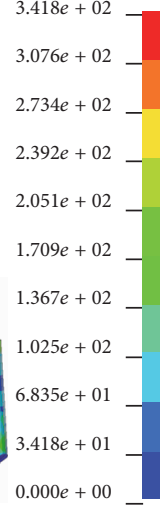

(d) $t=323.94$

FIGURE 9: Stress change for the rescue capsule.

TABLE 1: Parameters used in linear polynomial equation of state.

\begin{tabular}{lcccccccccc}
\hline Material & Density $\left(\mathrm{kg} / \mathrm{m}^{3}\right)$ & $C_{0}(\mathrm{pa})$ & $C_{1}$ & $C_{2}$ & $C_{3}$ & $C_{4}$ & $C_{5}$ & $C_{6}$ & $E\left(\mathrm{~J} / \mathrm{m}^{3}\right)$ & $V_{0}$ \\
\hline Air & 1.29 & $-1 \times 10^{5}$ & 0 & 0 & 0 & 0.4 & 0.4 & 0 & $2.5 \times 10^{5}$ & 1 \\
Methane/air mixture & 1.23 & 0 & 0 & 0 & 0 & 0.274 & 0.274 & 0 & $3.4 \times 10^{5}$ & 1 \\
\hline
\end{tabular}

TABLE 2: Parameters used in state equation of steel.

\begin{tabular}{lcccccccc}
\hline Steel & Yield strength/MPa & Elastic modulus/Gpa & Poisson's ratio & Specific heat $/ \mathrm{J}(\mathrm{kgK})^{-1}$ & Melting point $/{ }^{\circ} \mathrm{C}$ & $\mathrm{C}$ & $\beta$ & Failure strain $/ \varepsilon_{f}$ \\
\hline $\mathrm{Q} 460$ & 460 & 208 & 0.3 & $0.43 \times 10^{3}$ & 1250 & 5.0 & 0 & 0.35 \\
\hline
\end{tabular}

between pressure field shock wave and the capsule, indicating the mutual restriction and mutual influence between explosion flow field and the structure. At the moment of gas explosion, the explosion products were generated under high temperature and pressure and expanded quickly across part 2 to the surface of the capsule. Before the shock wave contacts the capsule, the peak pressure of the incident wave is about $0.328 \mathrm{Mpa}$ (see Figure 4(a)). However, as the shock wave contacts the capsule, the pressure increase rapidly to a peak pressure of $0.38 \mathrm{Mpa}$ at $293 \mathrm{~ms}$ (see Figure 4(b)) owing to incentive effect and the superposition effect of incident wave and the reflected wave, and a velocity gradient field was produced on the surface and surroundings of the capsule. The peak pressure of shock wave drops rapidly to $0.18 \mathrm{Mpa}$ at $304 \mathrm{~ms}$ due to energy absorbed by the capsule and tunnel as well as the multiple reflection and diffraction of shock wave (see Figure 4(c)). At the moment of $323.94 \mathrm{~ms}$, the peak pressure of the shock wave reduced to about $0.07 \mathrm{Mpa}$ (see Figure 4(d)).

Figure 5 shows the interaction between temperature field of shock wave and rescue capsule, indicating the mutual restriction and mutual influence between temperature field and the structure. At the moment of gas explosion, the explosion products generated under high temperature and 


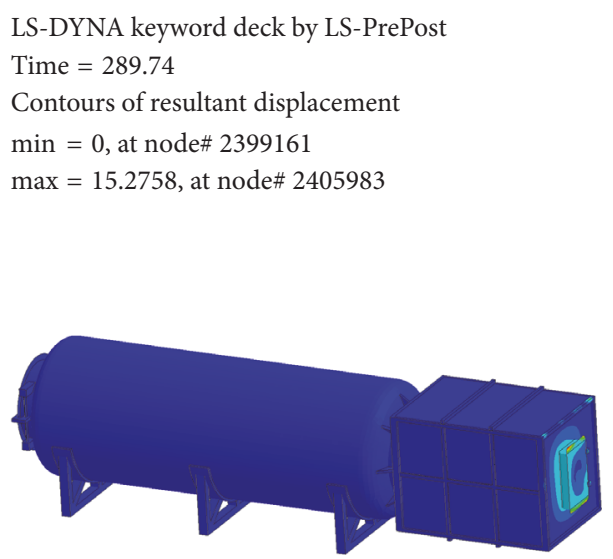

(a) $t=289.74$

LS-DYNA keyword deck by LS-PrePost

Time $=312.54$

Contours of resultant displacement

$\min =0$, at node\# 2399161

$\max =31.5167$, at node\# 2413953

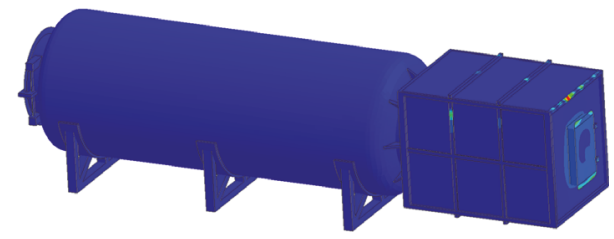

(c) $t=312.54$

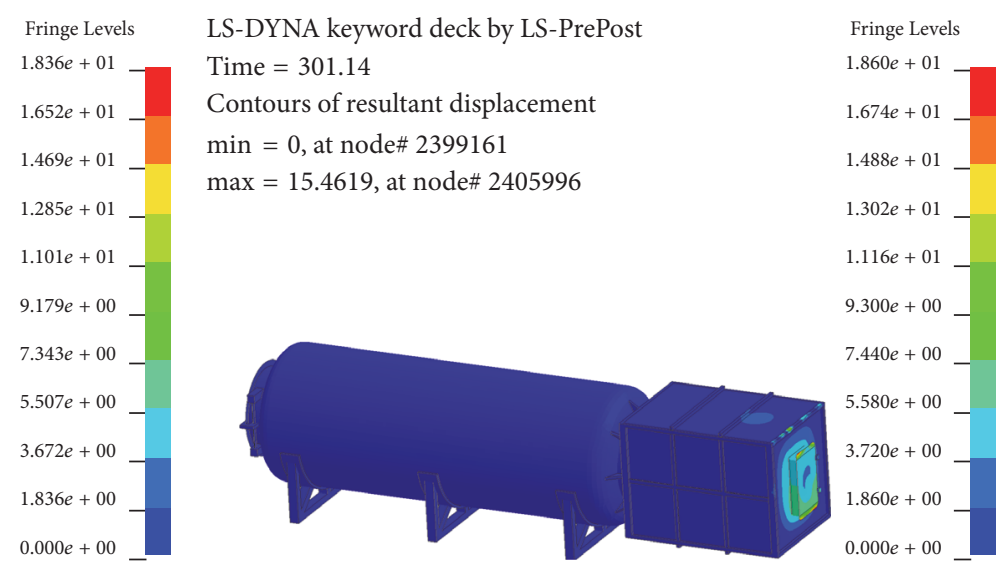

(b) $t=301.14$

LS-DYNA keyword deck by LS-PrePost

Time $=323.94$

Contours of resultant displacement

$\min =0$, at node\# 2399161

$\max =47.0967$, at node\# 2413953

$1.111 e+01$

$9.522 e+00$

$7.935 e+00$

$6.348 e+00$

$4.761 e+00$

$3.174 e+00$

$1.587 e+00$

$0.000 e+00$

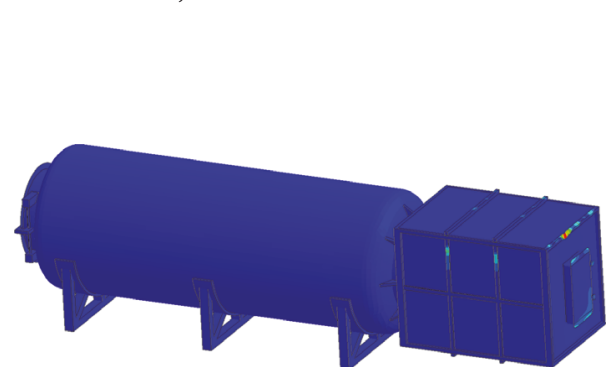

(d) $t=323.94$

FIgURE 10: Displacement change for the rescue capsule.

pressure and expanded quickly across part 2 to the surface of the capsule. Before the shock wave meets the capsule, the peak temperature value of the incident wave is about $1600^{\circ} \mathrm{C}$ (see Figure 5(a)). As the shock contacts the capsule, the shock wave temperature decreased to about $1200^{\circ} \mathrm{C}$ at $293 \mathrm{~ms}$ (see Figure 5(b)) owing to heat conduction and thermal convection, and a temperature gradient field was produced on the surface and surroundings of the capsule. The peak temperature of shock wave drops rapidly to $800^{\circ} \mathrm{C}$ at $304 \mathrm{~ms}$ due to endothermic effect, with the capsule and tunnel as well as the multiple reflection and diffraction of shock wave (see Figure 5(c)). At the moment of $323.94 \mathrm{~ms}$, the peak temperature of the shock wave reduced to about $620^{\circ} \mathrm{C}$ (see Figure 5(d)).

Figure 6 shows the coupling relationships between the explosion flow field, stress field, and temperature field. Interaction between each field can be expressed as follows: (1) the influence of thermal strain stress field and strain field was induced by temperature variation of gas explosion on stress field and strain field of the capsule. (2) The change of gas explosion pressure is caused by the temperature variation of gas explosion, thus directly affecting the interaction between explosion shock wave and the capsule. (3) The energy absorption performance, endothermic effect, and incentive effect of capsule lead to the change of explosion shock wave flow field and temperature field. (4) The influence of the change of the explosion flow field pressure on mechanical deformation of the capsule.

To obtain the pressure distribution characteristics on each side of the capsule, a series of measuring points were selected from the front, side, top, and back surface of the capsule structure. Figure 7 shows the distribution of the measurement points. Figure 8(a) shows the pressure-time curve in different measurement points on the surface. And it can be found that pressure-time curves of each measuring point in the front surface are essentially coincident curves which are basically consistent. At $287 \mathrm{~ms}$ time, pressure reaches a peak pressure of $0.73 \mathrm{Mpa}$. Due to the multiple diffractions and superposition of shock wave, the pressure curve fluctuates many times. Figure $8(\mathrm{~b})$ is the pressure-time curve of measured points on the back face, and it can be seen that the difference of peak pressure is great. The peak pressure value is almost $1 / 8$ of that on the front surface. In this section, the closer it is to the bottom of the capsule, the smaller the peak pressure is. Figures $8(\mathrm{c})$ and $8(\mathrm{~d})$ are the pressure-time curves of the monitoring points at the top and the side of the 

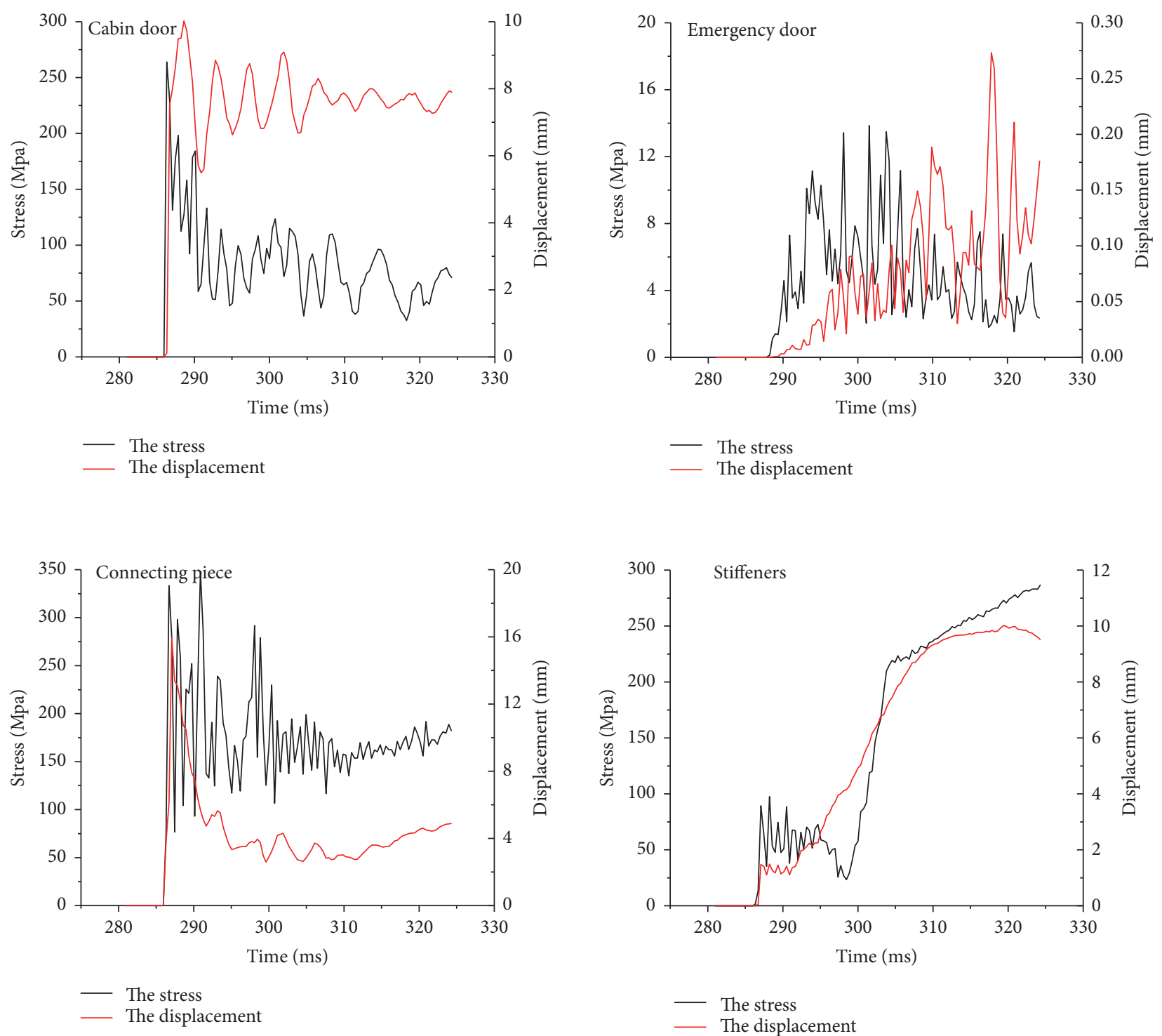

FIgURE 11: The maximum stress and displacement curves of the key components on the rescue capsule.

capsule, respectively. And it can be found that the pressure changes are almost the same along the longitudinal distance, and the peak pressure attenuates quickly on both sides.

\subsection{The Thermodynamic Response of a Rescue Capsule}

4.2.1. Stress Filed. Figure 9 shows the stress cloud chart of the capsule at different moments. As it can be seen from Figure 9, the equivalent stress of the capsule decreases first and then increases gradually with time during the process of shock wave interaction with the capsule. At the moment of $280 \mathrm{~ms}$, the shock wave reaches the surface of the capsule and begins to exert pressure. The equivalent stress on the edge of the impact face of the capsule is small and peak value reaches $235 \mathrm{MPa}$ at $289 \mathrm{~ms}$, however the stress of the side and the top is much smaller. Thereafter, the stress concentration zone begins to spread around, at the moment of $301 \mathrm{~ms}$, the stress concentration area locates in the 4 angles of the impact face, and the maximum equivalent stress reaches $300 \mathrm{MPa}$. The maximum equivalent stress reaches about $341 \mathrm{MPa}$ at $323 \mathrm{~ms}$ but does not exceed material yield strength. In the whole process of the explosion shock wave interaction with the rescue capsule, the strength of the whole structure is in elastic state. Due to the short interaction time between the explosion shock wave and the rescue capsule, the stress concentration and the plastic zone do not lead to the failure of the key components.

4.2.2. Displacement Field. Figure 10 shows the displacement field of the capsule at different moment. It can be seen that the peak value of displacement decreases with time in the process of shock wave interaction with the capsule. However, the largest deformation part exists in the front surface of the refuge capsule; this can be interpreted that the front surface was subjected to blast load and dynamic pressure as gas explosion occurred. In the whole process of the shock wave 


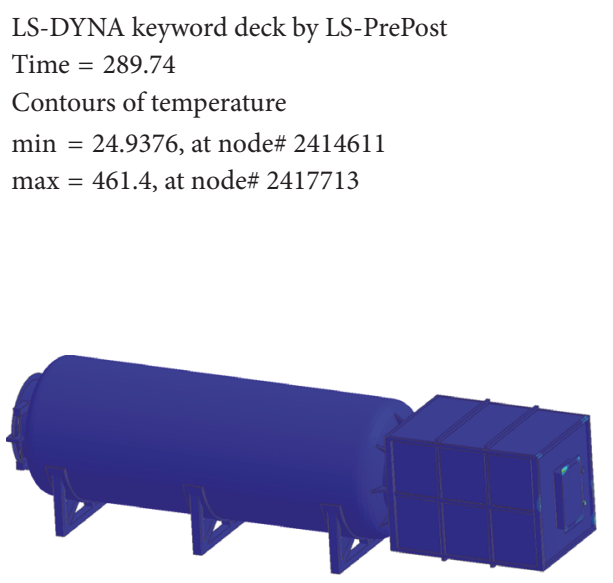

(a) $t=289.74$

LS-DYNA keyword deck by LS-PrePost

Time $=312.54$

Contours of temperature

$\min =24.9569$, at node 2414552

$\max =430.737$, at node\# 2417713

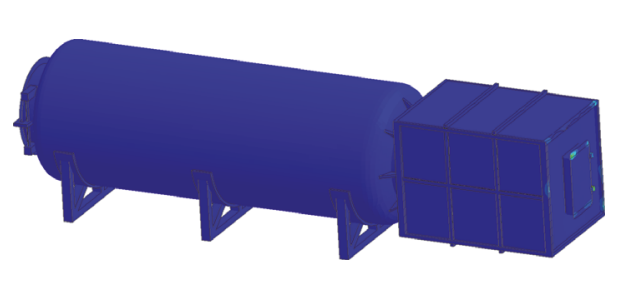

(c) $t=312.54$
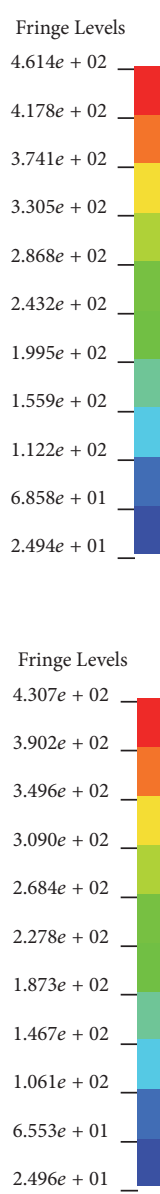
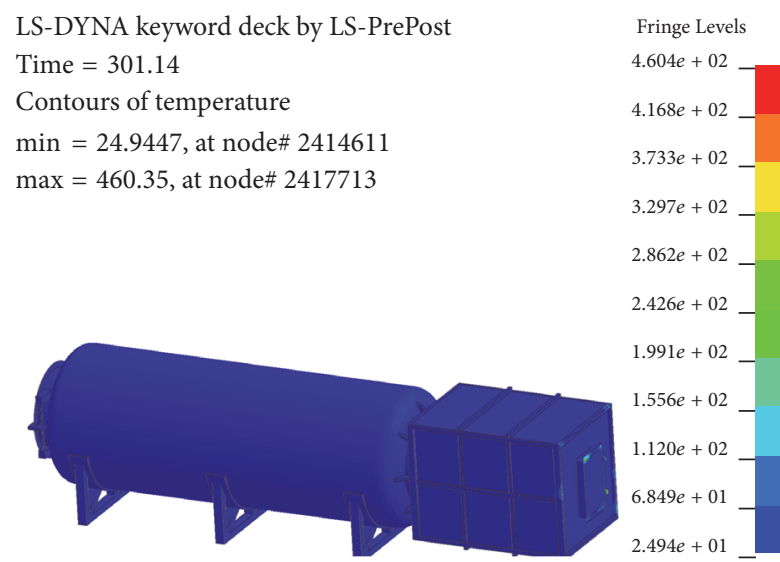

(b) $t=301.14$

LS-DYNA keyword deck by LS-PrePost

Time $=323.94$

Contours of temperature

$\min =24.9595$, at node\# 2414589

$\max =407.771$, at node\# 2417713

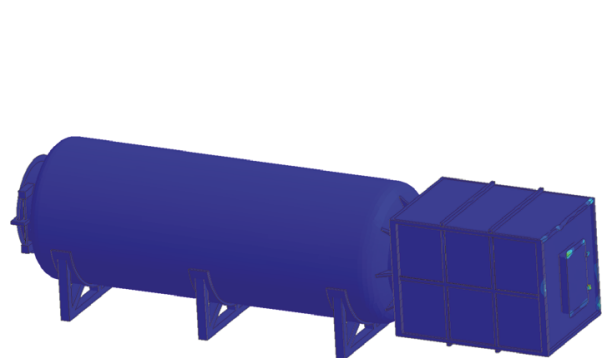

(d) $t=323.94$

FIGURE 12: Displacement change for the rescue capsule.

acting with the capsule, the largest deformation still occurs on the impact face. At the moment of $289 \mathrm{~ms}$, the maximum displacement of the capsule is about $18.36 \mathrm{~mm}$, which does not exceed the specified limit of deformation. When the peak pressure of the shock wave reaches the maximum, the whole structure and the strength of the main parts are in the elastic state. No local brittle fracture and cracks occur, illustrating that the good sealing of the capsule and the overall stiffness meet the safety requirements.

Figure 11 shows the stress-time and displacement-time curves of the largest stress element on the cabin door, emergency door, connecting pieces, and stiffeners, respectively. The maximum equivalent stress and displacement occur on the impact face due to the most intense dynamic response under gas explosion load. The stress and displacement of the escape door at the end of the capsule are relatively small due to the weak dynamic impact load. The maximum equivalent stress of cabin door, emergency door, connecting pieces, and stiffeners does not exceed the material yield strength. Moreover, the residual displacement of capsule of all units is less than limits of $12 \mathrm{~mm}$, which shows that the designed capsule has an excellent antiknock performance under gas explosion load.
4.2.3. Temperature Field. Figure 12 shows the temperature nephogram of the capsule at different moments, and higher temperature appears on hinge welded between the impact face and the cabin door and reaches about $460^{\circ} \mathrm{C}$ in the whole process of shock wave interaction with the capsule; however, the melting point is $1300^{\circ} \mathrm{C}$ high; therefore, the sealing performance and variation of stress and displacement between the two sections are less affected by the hinge. The rest of the structure is basically in normal state. Although the gas explosion can quickly reach about $2000^{\circ} \mathrm{C}$, a huge heat amount transfers through flow and heat conduction and heat radiation with the capsule after the explosion. On the one hand, due to the short period between shock wave interactions with rescue capsule, the heat transferred is less. On the other hand, the heat coefficient steel selected in this paper is low, and therefore it is not conducive to heat transfer in a short time. As a result, the temperature changes little owing to the small heating rate. In the whole process, the deformation is reasonable and sealing performance shows a good trend, and thus the temperature on capsule is still in the normal state, which shows that the capsule has a definitely excellent antihigh-temperature performance under gas explosion load and meets the requirement of coal mine safety production. 


\section{Conclusions}

(1) The numerical model of capsule, air/gas mixture, and the tunnel was established by using ANSYS/LS-DYNA, and the thermal-fluid-solid coupling mechanism of gas explosion shock wave interaction with rescue capsule was revealed using ALE coupling algorithm.

(2) During the process of gas explosion shock wave interacts with rescue capsule, the peak value of equivalent stress decreases first and increases thereafter. The peak value of displacement decreases against time. The overall structure and the strength of the main parts are still in elastic state. No brittle fracture appears on the whole capsule, and it is demonstrated that the design, sealing performance, and overall stiffness of the capsule meet the safety requirements.

(3) The fact that the shock wave would be intensified by the obstacle has been confirmed. Due to many diffractions and superpositions of the shock wave, the pressure curve waves many times. The peak pressure value on the back face is nearly $1 / 8$ of that on the front face. The variation laws of pressure on the top and side were basically the same, decrease along the longitudinal distance gradually, the peak pressure of different monitoring points on each decrease rapidly.

(4) In the process of gas explosion shock wave interaction with rescue capsule, higher temperature appears on hinge welded between the impact face and the cabin door, and the rest of the structure was still in normal state. During the whole course, deformation capsule was reasonable and sealing performance showed a good trend, so the temperature rescue cabin is still in the normal state. The capsule has a definitely good anti-high-temperature performance under gas explosion load and meets the requirement of coal mine safety production.

\section{Conflicts of Interest}

The authors declare that there are no conflicts of interest regarding the publication of this paper.

\section{Acknowledgments}

This work was supported by the National Natural Science Foundation of China (Grants no. 51404195 and no. 51504190), project funded by China Postdoctoral Science Foundation (Grant no. 2016M592819), and Key Projects of Prevention and Controlling Technology of Major Accidents for Safety Production (Grant no. shanxi-0008-2016AQ).

\section{References}

[1] H. Niu, J. Deng, X. Zhou, and H. Wang, "Association analysis of emergency rescue and accident prevention in coal mine," Procedia Engineering, vol. 43, pp. 71-75, 2012.

[2] C. Yang, X. Li, Y. Ren, Y. Zhao, and F. Zhu, "Statistical analysis and countermeasures of gas explosion accident in coal mines," Procedia Engineering, vol. 84, pp. 166-171, 2014.

[3] K. A. Margolis, C. Y. K. Westerman, and K. M. KowalskiTrakofler, "Underground mine refuge chamber expectations training: program development and evaluation," Safety Science, vol. 49, no. 3, pp. 522-530, 2011.

[4] Department of Labor, "Mine safety and health administration," Federal Register, vol. 73, no. 25, pp. 656-700, 2008.

[5] M. D. Mitchell, Analysis of Underground Coal Mine Refuge Shelters [Ph.D. Thesis], West Virginia University, 2008.

[6] K.-F. Zhang, M. Zhu, Y.-J. Wang, E.-J. Fu, and W. Cartwright, "Underground mining intelligent response and rescue systems," in Proceedings of the 6th International Conference on Mining Science and Technology, ICMST 2009, vol. 1, pp. 1044-1053, China, September 2009.

[7] K. Wang, S. Jiang, X. Ma, Z. Wu, W. Zhang, and H. Shao, "Study of the destruction of ventilation systems in coal mines due to gas explosions," Powder Technology, vol. 286, pp. 401-411, 2015.

[8] H. F. Fang, S. R. Ge, and E. Y. Hu, "Loading impact study of refuge chamber layout on its blast airtight door," Coal Mine Safety, vol. 43, no. 5, pp. 19-22, 2012.

[9] J. Y. Richard Liew and H. Chen, "Explosion and fire analysis of steel frames using fiber element approach," Journal of Structural Engineering, vol. 130, ASCE, no. 7, pp. 991-1000, 2004.

[10] Z. T. Hou, W. Kuang, and B. Liang, "The selection of shell shape for mine-used movable rescue capsule," Coal Mine Safety, vol. 43, no. 3, pp. 125-128, 2013.

[11] P. X. Xu and Y. Hu, "Optimum design and test research for rescue chamber," Journal of Ship Mechanics, vol. 15, no. 11, pp. 1264-1269, 2011.

[12] X. T. Fan, "Experimental study of anti-explosion of movable mine rescue chamber," Mining Safety and Environmental Protection, vol. 37, no. 3, pp. 25-30, 2010.

[13] P. H. Guo, G. T. Jiao, and J. Han, "Anti-explosion performance and numerical simulation optimization of refuge chamber," Mechanical Engineering \& Automation, vol. 189, no. 2, pp. 9697, 2015.

[14] L. D. Ma, H. Y. Pan, and Y. Wang, "Numerical simulation of a refuge chamber resisting gas explosion impact," Journal of Vibration and Shock, vol. 31, no. 20, pp. 172-176, 2012.

[15] H. Zhao, X.-M. Qian, and J. Li, "Simulation analysis on structure safety of coal mine mobile refuge chamber under explosion load," Safety Science, vol. 50, no. 4, pp. 674-678, 2012.

[16] H. Zhao and X. Qian, "Simulation analysis on structure safety of two typical refuge chamber shell forms under explosion load," in Proceedings of the 2012 8th International Symposium on Safety Science and Technology, ISSST 2012, pp. 910-915, Procedia Engineering, China, 2012.

[17] Y. X. Zeng, C. H. J. P. Bai, and Li, "Numerical simulation of rescue cabin under blasting in the tunnel," Journal of China Coal Society, vol. 37, no. 120, pp. 1705-1708, 2012.

[18] H. Y. Wang, T. Cao, and X. Q. Zhou, "Research and application of attenuation law about gas explosion shock wave in coal mine," Journal of the China Coal Society, vol. 34, no. 6, pp. 778-782, 2009.

[19] J. L. Yang, Y. Z. Ma, and L. W. Yang, "Explosion-proof performance analysis of mine refuge chamber," Journal of China Coal Society, vol. 38, supplement 1, pp. 159-163, 2013.

[20] R. B. Mei, C. S. Li, and B. Cai, "FEM analysis of antideformation capability for coal mine refuge chamber suffered to gas explosion," Journal of Northeastern University, vol. 34, no. 1, pp. 85-94, 2013.

[21] L. Zhang, Mine Rescue Chamber Dynamic Numerical Simulation Analysis and Structure Optimization [M.S. thesis], Xi'an University of Science and Technology, 2013. 
[22] X. R. Wang, H. Zhu, and J. K. Gao, "Insulating properties of mobile refuge chamber for coal mine," Coal Mine Machinery, vol. 32, no. 3, pp. 61-62, 2011.

[23] B. Zhang, W. Zhao, W. Wang, and X. Zhang, "Pressure characteristics and dynamic response of coal mine refuge chamber with underground gas explosion," Journal of Loss Prevention in the Process Industries, vol. 30, pp. 37-46, 2014.

[24] G. Li, The Design \& Research on The New Type of Mobile Mine Capsule [M.S. thesis], Qingdao University of Science \& Technology, 2013.

[25] M. Du, Body Research \& Test Analysis on Mobile Refuge Chamber [M.S. thesis], Qingdao University of Science \& Technology, 2013.

[26] H. Fang, S. Ge, L. Cai, and E. Hu, "Buckling analysis of the shell of a refuge chamber in a coal mine under uniform axial compression," International Journal of Mining Science and Technology, vol. 22, no. 1, pp. 85-88, 2012.

[27] H. F. Fang, L. Cai, and M. Wang, "Dynamic response of coal mine refuge chambers shell under gas explosion load," Energy Education Science and Technology Part A: Energy Science and Research, vol. 32, no. 6, pp. 5221-5228, 2014.

[28] B. Liu, Research on working environment of coal mine rescue chamber and heat-insulation and anti-explosion properties of chamber structure [M.S. thesis], Harbin Institute of Technology, 2012.

[29] B. Bai, Study on the explosive and thermal-shock resistance performance of refuge chamber [M.S. thesis], Taiyuan University of Science \& Technology, 2014.

[30] M. G. Song and S. R. Ge, "Dynamic response of composite shell under axial explosion impact load in tunnel," Thin-Walled Structures, vol. 67, pp. 49-62, 2013.

[31] H. Yalciner, "Structural response to blast loading: the effects of corrosion on reinforced concrete structures," Shock and Vibration, vol. 2014, no. 7, Article ID 529892, 7 pages, 2014.

[32] J. H. S. Lee, "Explosion in vessels: recent results. New data on explosions in closed and vented vessels provide valuable tools for loss-prevention engineers," Plant/Operations Progress, vol. 2, no. 2, pp. 84-89, 1983.

[33] J. Y. R. Liew, "Survivability of steel frame structures subject to blast and fire," Journal of Constructional Steel Research, vol. 64, no. 7-8, pp. 854-866, 2008.

[34] G. S. Cowper and P. R. Symonds, "Strain-hardening and strainrate effects in the impact loading of cantilever beams," Tech. Rep. No. 28, Contract Nonr-562(10), NR-064-406, Providence (RI): Division of Applied Mathematics, Brown University, 1957. 


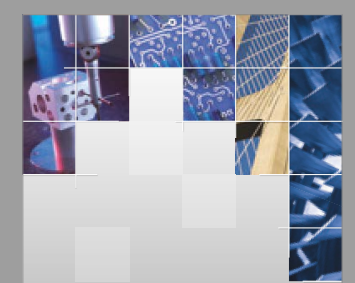

\section{Enfincering}
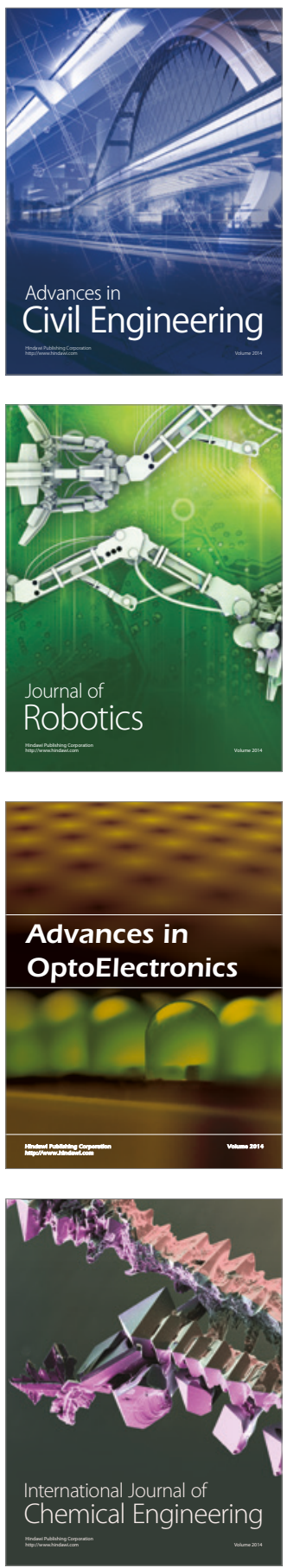

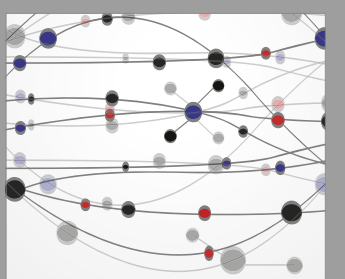

The Scientific World Journal

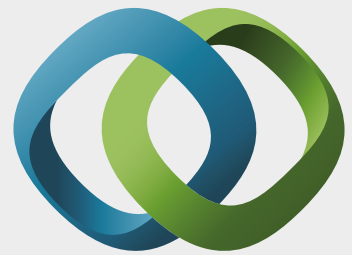

\section{Hindawi}

Submit your manuscripts at

https://www.hindawi.com
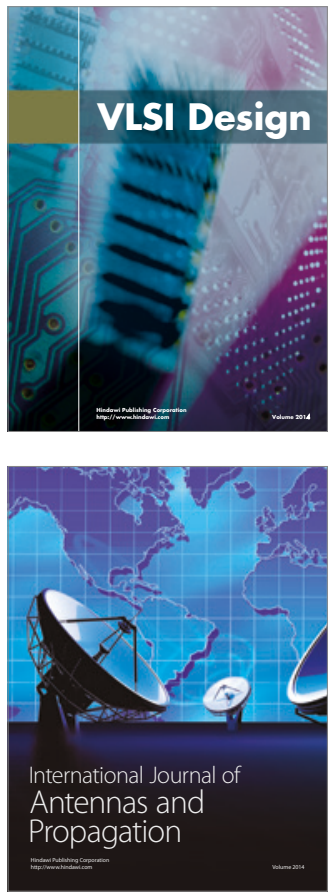

\section{Rotating}

Machinery
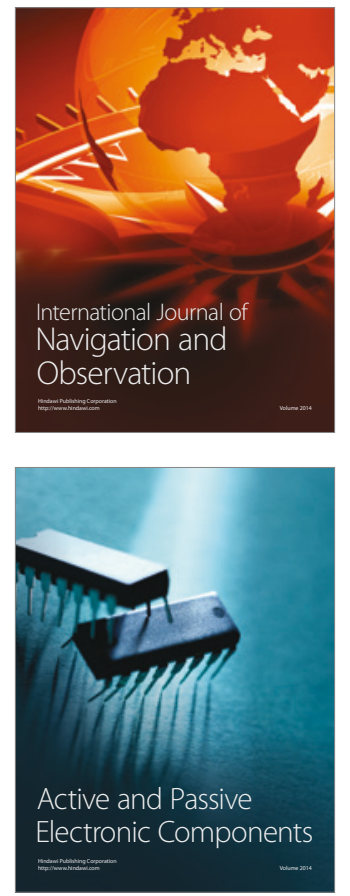
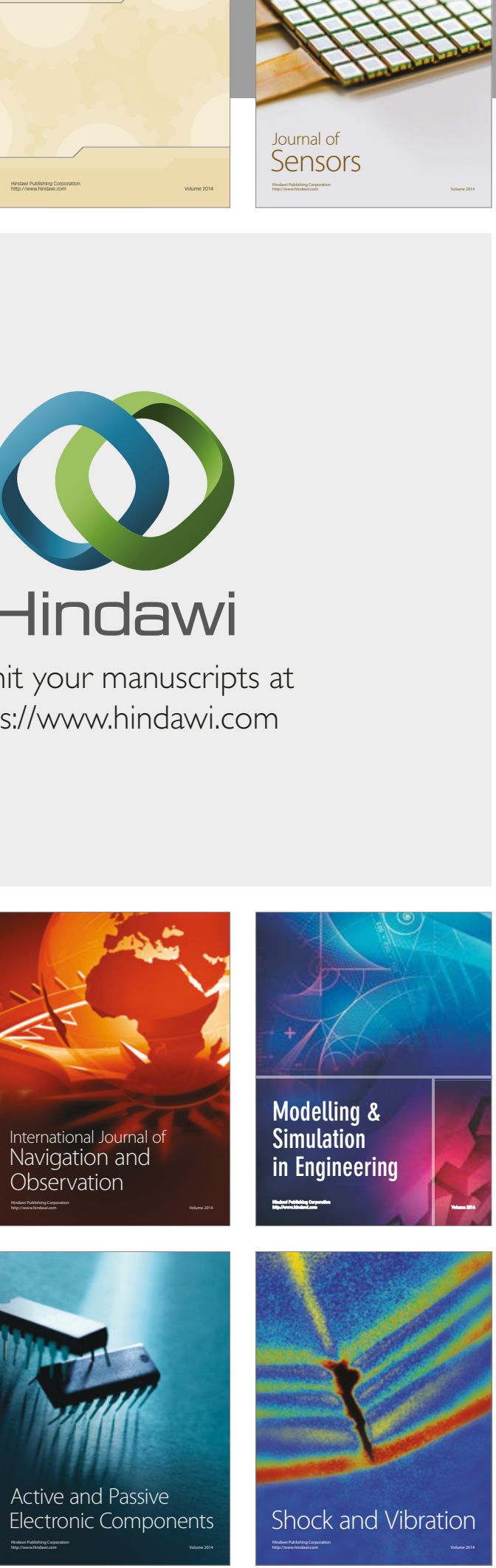
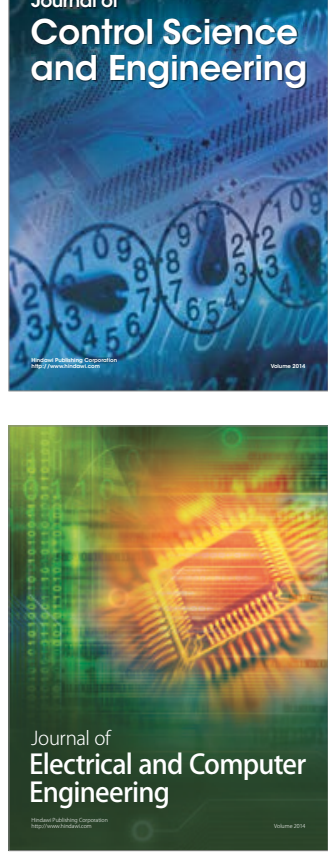

Distributed

Journal of

Control Science

and Engineering
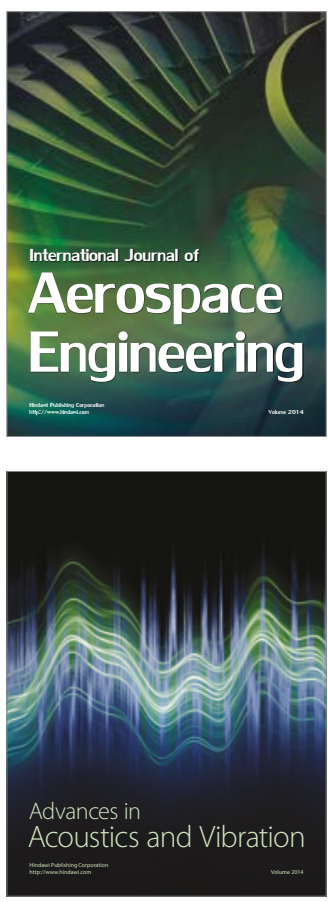

Sensor Networks 